\title{
GW23-e1081 ASSOCIATIONS OF THE SERUM LEUKOTRIENE B4 LEVEL WITH ARACHIDONATE 5-LIPOXYGENASE ACTIVATING PROTEIN GENE POLYMORPHISMS AND THE RISK OF ACUTE CORONARY SYNDROME
}

doi:10.1136/heartjnl-2012-302920k.41

He Guo-Ping, Ye Shan, He Guo-Ping. Affiliated Wujin Hospital of Jiangsu University, Changzhou 213002, China

Objectives To explore the associations of the arachidonate 5-lipoxygenase activating protein (ALOX5AP) gene SG13S114T/A or SG13S89G/A polymorphisms with the serum leukotriene (LT) B4 levels in acute coronary syndrome (ACS) patients and subjects without coronary artery disease $(\mathrm{CAD})$ from Chinese Han population of Sunan region for providing laboratory data in the further research of effects of LTB4 on the ACS pathogenesis.

Methods In the same individuals, the ALOX5AP gene SG13S114T/A or SG13S89G/A polymorphisms was genotyped by polymerase reaction-restriction fragment length polymorphism analysis and the serum LTB4 level (M/IOR) was measured by ELISA in 508 cases of ACS patients (ACS group) and 201 subjects without coronary stenosis (control group).

Results (1) The serum LTB4 levels in ACS group significantly were higher than those in the control group (470.27/316.32 vs 233.05/ $226.82 \mu \mathrm{g} / \mathrm{ml}, \mathrm{p}<0.001)$; after adjusting for traditional CAD risk factors such as gender age, smoking, hypertension, diabetes and dyslipidemia by the Logistic regression analysis, there was a significant correlation of the serum LTB4 levels with the risk of ACS $(\mathrm{OR}=6.454$, $95 \%$ CI 4.203 to 9.911, p<0.001). (2) In the ACS group and control group, there were no significant difference of the serum LTB4 levels among any genotypes (AA, AT and TT) of the ALOX5AP gene SG13S114T/A or between GG and $(\mathrm{GA}+\mathrm{AA})$ genotypes of the ALOX5AP gene SG13S89G/A (all p>0.05).

Conclusions Conclusion: In Chinese Han crowd of Sunan region, elevated serum LTB4 levels is relevant to risk of ACS, but there are no associations of the ALOX5AP gene polymorphisms with elevated serum LTB4 levels in ACS patients and subjects without coronary stenosis. 